\title{
Electro Chemical Honing of External Cylindrical Surfaces- AN INNOVATIVE STEP
}

\author{
RAO, P.S.; JAIN, P.K. \& DWIVEDI, D.K.
}

Abstract: Electrochemical honing is one of the most precision machining process used for finishing of cylinders and gears, based on the combination of electrochemical machining and conventional honing process. ECH is well known process for difficult to cut and hard materials as long as it is electrically conductive. This made ECH process an ideal choice for improving the surface quality of critical components like Inconel, Incolay, Titanium \& Nickel alloys etc. It describes the design and fabrication of an indigenously developed tooling setup for ECH of external cylindrical components. Titanium alloy and EN8 Steel are used as work piece material for carryingout the experimentations to study the effect of four key process parameters for better surface finish and material removal aspect. The key features of the newly developed experimental setup guides the future research with an objective to revive an interest of the global research community to further mature this process.

Key words: Electro Chemical Honing, Ti $6 \mathrm{Al} 4 \mathrm{~V}$ alloy \& EN8 steel, Process Parameters and Comparison
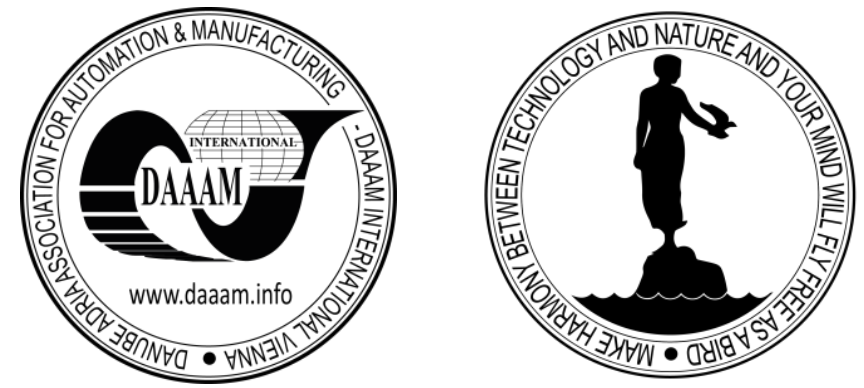

Authors' data: Research Scholar Rao, P[atange] S[udhakar]; Prof. Jain, P[ramod] K[umar]; Prof. Dwivedi, D[heerendra] K[umar];Mechanical \& Industrial Engineering Department, IITRoorkee, Roorkee, INDIA, psrao.iitr@gmail.com, psraodme@iitr.ernet.in

This Publication has to be referred as: Rao, P[. Sudhakar]; Jain, P[ramod Kumar] \& Dwivedi, D[heerendra Kumar] (2015). Electro Chemical Honing of External Cylindrical Surfaces - An Innovative Step, Chapter 09 in DAAAM International Scientific Book 2015, pp.097-116, B. Katalinic (Ed.), Published by DAAAM International, ISBN 978-3-902734-05-1, ISSN 1726-9687, Vienna, Austria DOI: $10.2507 /$ daaam.scibook.2015.09. 
Rao, P. S.; Jain, P. K. \& Dwivedi, D. K.: Electro Chemical Honing of External Cyli...

\section{Introduction}

In this modern scenario with drastic development in advanced technology more and more challenges are faced by the engineers and researchers in the field of manufacturing and production. Most of the manufacturing industries are specially focusing on dimensional accuracy and surface finish. The rapid development in advanced industries like aerospace, automobile, nuclear power and turbine industries has been accompanied by the development of very hard, high strength, difficult-tomachine, non-ferrous materials and alloys (Merchant, 1961). In order to improve the tribological properties, fatigue strength and corrosion resistance, a reasonably good surface finish is desired. Producing complicated geometries and maintaining high dimensional accuracy in such materials become extremely difficult with the conventional machining methods. This necessitates the exploration of Advanced Manufacturing Processes (AMPs) (Pandey \& Shan, 1980). Hybrid Manufacturing Processes are conceptualized by combining either two or more than two AMPs or AMPs and Conventional Process to simultaneously exploit the potentials and capabilities and also to minimize the adverse effects of individual. Electro Chemical Honing $(\mathrm{ECH})$ is one of the Advanced Manufacturing Process which is having more scope in coming modern scenario (El-Hofi, 2005). ECH process have their own advantages to remove any hard material with controlled surface generation with excellent surface finish. Furthermore, it provides highest productivity and increasing the service life of the components (Chen et al.,1981). However, so far these investigations were carried out to provide precision finishing to the internal cylinders as well as gears (Dubey, 2008) (Misra et al., 2011). After that a number of researchers were carried out detailed study on ECH of various gears (Misra et al., 2012) (Shaikh \& Jain, 2013). It is now one attempt to carry out the research on ECH of an external cylindrical surfaces to discuss the development of productive, highaccuracy and good surface finishing method based on ECH principle. The electro chemical honing process is even used to obtain precise dimensions and surfaces in cylindrical shapes with a wide range of diameters. This process applies to parts such as Hydraulic Cylinders, Pistons, Bearing Bores, Pin Holes, Gun barrels and to some extent external cylindrical shafts. This describes about the surface finishing of external cylindrical surfaces of EN8 steel material as well as titanium alloy Ti6Al4V by this ECH process. However, many researchers are studied different surface characteristics of EN8 steel and Ti6Al4V by other advanced manufacturing processes like EDM, ECM etc to achieved better surface capabilities (Sunil et al., 2014). Most researchers are discussed for better surface finish $\mathrm{Ra}$ and more material removal aspects and their affect on advanced machining processes.

\section{Titanium alloy and EN8 steel}

Titanium alloys are extensively used in aerospace, petroleum and chemical industry due to their specific strength, fracture resistance, strong corrosion resistance and ability to retain high strength at elevated temperatures. By the characteristics of low density and high strength titanium alloys Ti6Al4V are widely used in mechanical 
engineering, especially in the fields of aerospace, automoble and medical engineering. Recently, the titanium and its alloys are also widely used as biomedical materials to act as a load bearing implant in orthopaedic surgery However, titanium and its alloys have poor machinability due to their low thermal conductivity, high chemical reactivity and low modulus of elasticity resulting in high cutting temperature and rapid tool wear (Lu \& Leng, 2005). During machining of titanium and its alloys by conventional processes, the above characteristics lead to high temperature at cutting interfaces. Keeping in view the severity of machining of titanium and its alloys by conventional machining processes, the need of development of newer concept for machining of titanium with hybrid process is explored . Among advanced machining processes, electrochemical honing (ECH) is to be used for the purpose of machining Ti alloys because of its many favourable features. The process is particularly useful for rapid removal of metal from the surface. In this, the material is removed at an atomic scale by electrolytic dissolution and mechanical honing abrasive action for Ti alloy (Rao et al., 2014). Therefore, the process can produce good surface finish and moreover, it has no damaging effect on the mechanical properties of the metal (Burr \& Oliver, 1968). Among other advanced machining processes, electrochemical honing $(\mathrm{ECH})$ is one of the latest process which can be used for machining of EN8 Steel also because of its feasible favorable features of low cost availability (Rao et al., 2015). EN8 steel is widely used in mechanical engineering, especially in the fields of automobile, machine building division, process industries and production workshop as Ti is used for aerospace and allied Industries.

\section{Electro chemical honing}

Electro chemical machining with additional conventional process has lead to ECH process. In Electro Chemical Honing process, the more material is removed at an atomic scale by electrolytic dissolution and the rest by mechanical honing abrasive action and is particularly useful for rapid removal of metal from the surface. Electrochemical honing $(\mathrm{ECH})$ is a hybrid micro finishing technology characterized by a distinct coupling of electrochemical machining (ECM) and conventional mechanical honing $(\mathrm{MH})$ processes to provide controlled functional surface generation and fast material removal capabilities in a single operation (Benedict, 1987).

The ability of ECH to apply these benefits productively, has led to its widespread use in industries, especially in aerospace, automobiles, petrochemical reactor, roller and gear manufacturing industries. ECH can offer a unique range of benefits to the machined surface which cannot be obtained by either of the processes when applied independently (Budzynski, 1989). The ECH process is five to eight times faster than honing and four times faster than grinding. It can provide surface finish up to $0.05 \mu \mathrm{m}$. It provides fine surface generation by honing and fast material removal by ECM in a single operation (Dubey, 2006). The ECH process offers advantages of high metal removal rate and extreme accuracy of $0.001 \mathrm{~mm}$ in a wide variety of hard to cut materials. The other advantages include the ability to correct out 
Rao, P. S.; Jain, P. K. \& Dwivedi, D. K.: Electro Chemical Honing of External Cyli...

of roundness, cylindricity, circularity and axis straightness in relatively round cylindrical work pieces. Work piece bore length-to-diameter ratios of 1.5:1 and longer are ideal for the ECH process. In this ECH finishing operation more amount of material is removed by electrolyte dissolution and a very small amount of material is removed from the workpiece by means of a honing process (He et al, 2000) (Bannard, 1976). In electrochemical honing process the workpiece and the tool were made anode and cathode respectively, separated by an electrolyte. When the current is passed through the electrolyte, the anode dissolves locally specularly obtaining the cathode (Misra et al., 2013). However, developing an ECH process for the material removal is not simple, due to generation of a passive oxide layer surface on workpiece materials the layer must be removed in a controlled manner by mechanical honing process (Singh \& Jain, 2014). So honing plays a very important mechanism in the ECH process. Keeping in view the severity of machining, a honing abrasive is also used in non conventional machining processes. Therefore, the process can produce good surface finish and also, it has no damaging effect on the mechanical properties of the metal. The combination of various properties of EN8 and Ti alloy leads to machine by unconventional process against other conventional processes. $\mathrm{ECH}$ has the advantage of not causing thermal distortion on the machined surface.

\section{Experimental details}

\subsection{Experimental setup}

The application of ECH for surface finishing of external cylinders has not been given kind attention so far and as a consequence even no such experimental setup has been reported neither from the academicians nor from the industrialists. Electro Chemical Honing process involves the electrolytic dissolution and mechanical scrubbing, the design, fabrication and material selection can achieve based on some relevant considerations such as electrical conductivity, anti-corrosiveness, electrical insulation, machinability and economic feasibility. Therefore, based on objectives of study an experimental setup for surface finishing of external cylinders has been developed for the work pieces of EN8 Steel and Titanium alloys. The setup consists of power supply system, electrolyte supply system, tooling system, tool motion system and machining chamber and fixtures. A schematic diagram has been shown in Fig.1. The power supply system consists of $0-100 \mathrm{~V}$ and 100A DC supplying unit having provision for operating at both continuous and pulsating condition. The electrolyte supply system is consisting of reservoir, pump, flow meter, pressure gauges, heat exchanger, chamber drains, magnetic filters and settling tank etc. This subsystem is employed to provide power supply to the anodic work piece and cathode tool to complete the electric circuit. The purpose of this sub-element is to supply the filtered electrolyte with controlled flow rate and pressure to the machining zone. The entire tooling system is enclosed in a machining chamber. Machining chamber also has provisions for supply of fresh electrolytes, for removal of used electrolyte, and for escape of gases generated during ECH process. The machining chamber is connected to the cast iron frame using four brass screws. Thus, it is attached to the machine column of bench drilling machine using a swivel arrangement for ease in 
loading and unloading. The swivel system can slide on the machine column to achieve axial positioning of the tool with respect to work piece. The machining chamber is made of perspex to obtain a better visibility of the operation. Machine chamber consists of work piece fixture and ECH tool holder as shown in Fig.2. The work-holding system consists of a fixture and an electrolyte chamber and is attached to the foundation with proper insulating arrangements. The fixture and the electrolyte chamber are made of stainless steel and perspex respectively. Automatic gauging devices, such as air gauge, are often built into the ECH setup. The worktable and machine chamber fixture design considerations include corrosion resistance and strength to take over the machining torque without deforming the work-piece.

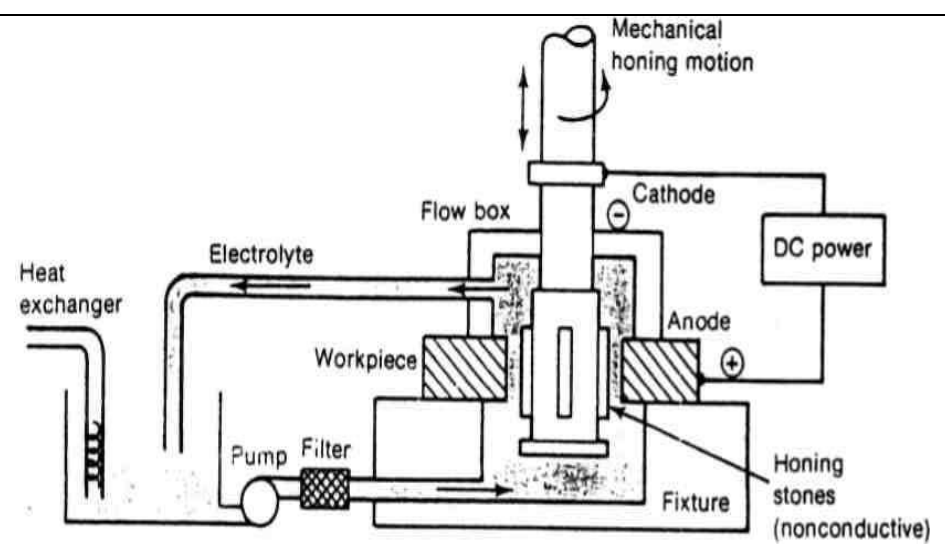

Fig. 1. Schematic view of ECH tool with work piece interaction

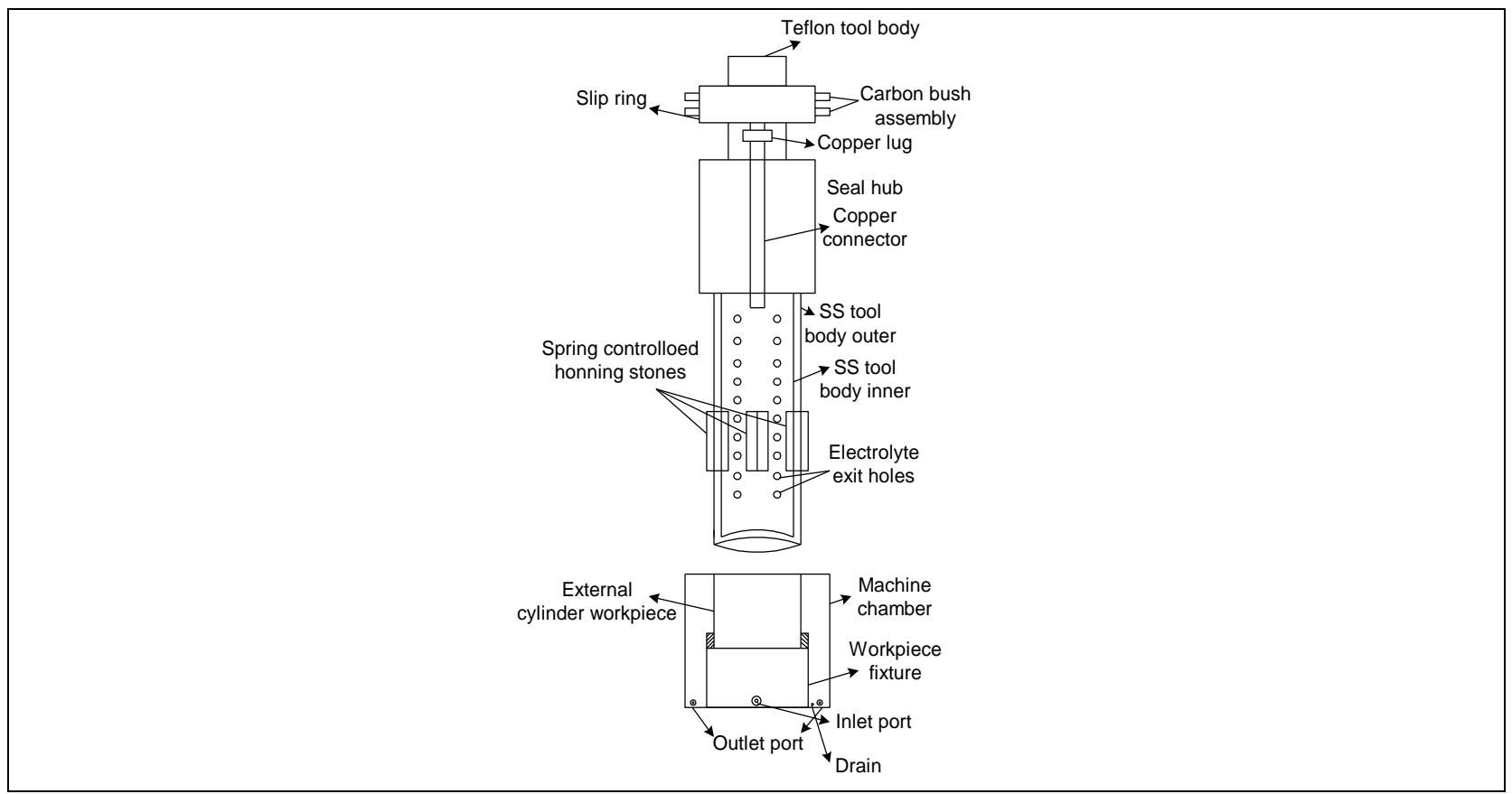

Fig. 2. Exploded view of ECH tool with work piece fixture

The inter-electrode gap (IEG) is maintained between workpiece and the tool to avoid short circuiting, and filled with the electrolyte. During this, non-conductive spring controlled honing tool is applied with controlled pressure on the workpiece. The abrasive action of the honing tool as shown on Fig.3. removes the material from 
Rao, P. S.; Jain, P. K. \& Dwivedi, D. K.: Electro Chemical Honing of External Cyli...

the outer surface of work piece, as the tool is designed for external cylindrical surface components. Then the honing tool as shown in Fig.4. is given simultaneous rotary and reciprocatory motions, as in conventional honing, to finish the workpicece surface. The study also investigates the effects of process parameters on microstructure and surface roughness of the machined surface.The mechanism of material removal in $\mathrm{ECH}$ is based on the interaction between electrolytic action with mechanical abrasion. Then the tool rotates and reciprocates while the work piece is stationary fixed in machine chamber. This rotary \& reciprocation movement of ECH tool is the single most important point in achieving the closer tolerances required and surface finish desired. Honing stones comprise an embedded abrasive particles (Al2O3, SiC, CBN) bonded in vitreous bonding material with particular grit size honing stones. The honing stones are mounted on a stain less steel tool holder which is simultaneously given a rotary motion as well as reciprocating (or oscillatory) motion to perform a complete cycle. The rotary movement of tool can be controlled by stepper motor and while reciprocating motion can be controlled by Micro controlled based programme. The reciprocating motion is along the axis of the work piece to bring the entire work surface in contact with the honing stone. 600 Grit size SIC honing stones are used to perform the experimentations for EN8 steel and Ti alloy work pieces. Selection of the abrasive type and size (80 to 600 mesh size) depends on the type of work piece and the rate of surface finish required.

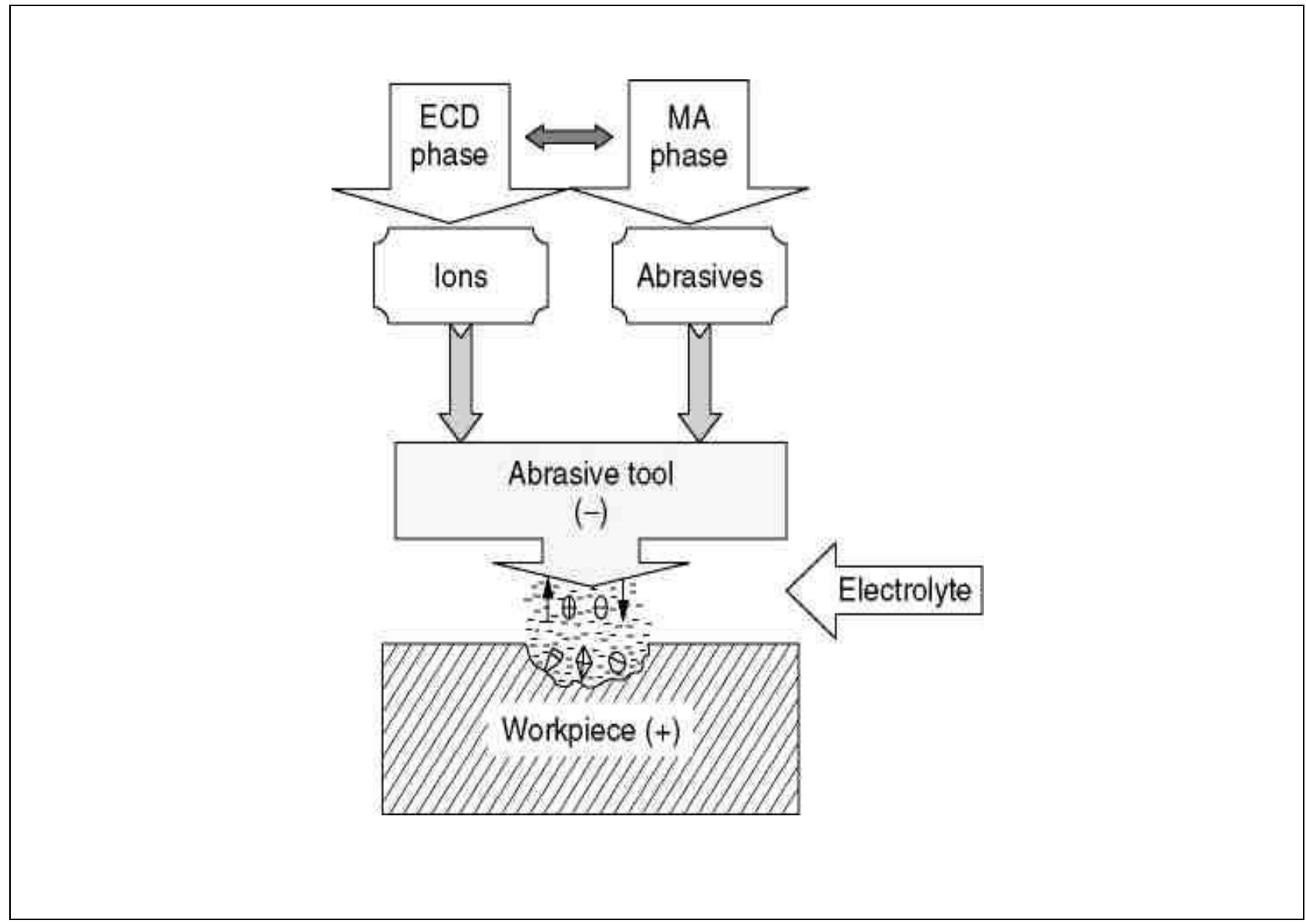

Fig. 3. Schematic view of ECM and Honing 


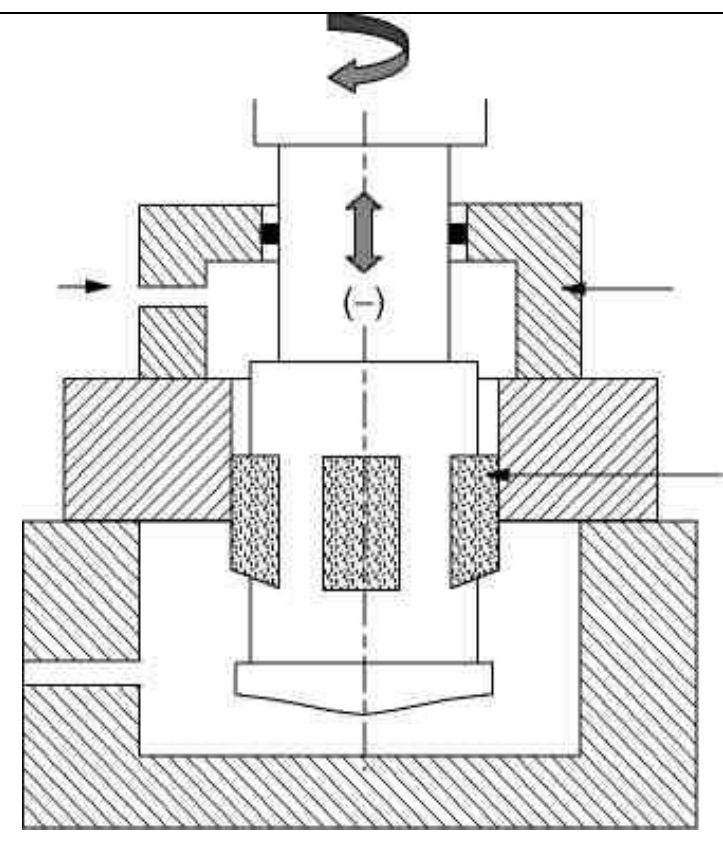

Fig. 4. Schematic view of ECH (El Hofi, 2005)

\subsection{Experimental procedure}

Experiments were carried out to study the effect of process parameters on process performance. The experiments have been done by using by varying one parameter i.e., One-Factor-At-a-Time (OFAT) approach. Finishing time, and three electrolyte-related parameters (i.e., composition, temperature and concentration) have been used as key process parameters to study their effect on the surface finishing performance of ECH on Ti alloy and EN8 Material. Initially the Effect of finishing time has been examined through experiments by varying one factor at a time approach and also later electrolyte composition, electrolyte temperature and electrolyte concentration have been studied. The surface roughness values before and after ECH are measured. In this work, processing time was used as input process parameter and surface texture parameters were used as response parameters. Table 1 and Table 2 presents the input and fixed process parameters selected for the experimentation for Ti alloy and EN8 material respectively. The parameters and their ranges were selected on the basis of literature review, pilot experiments and machining constraints.

The surface roughness characteristics (i.e. Ra), micro-hardness and surface integrity aspects were also examined. The surface roughness parameters were measured by Wyko NT 1100 optical profilometer. The percentage improvements in surface roughness values were also calculated to visualize the improvement in the surface quality of Ti alloy and EN8 Steel. Pre-experiment and post-experiment measurements of process performance characteristics were examined using the suitable measuring instrument like Scanning Electron Microscopy (SEM) and Atomic Force Microscopy (AFM) for electro chemically honed external cylinders of Ti alloy and EN8 Steel. The Composition of Ti alloy and EN8 steel obtained by EDX (Energy Dispersive X-ray) were shown in Fig.5.(a) and Fig.5.(b) respectively. The FESEM Composition of Ti alloy and EN8 were shown in Table 3(a) and Table 3(b) respectively. 
Rao, P. S.; Jain, P. K. \& Dwivedi, D. K.: Electro Chemical Honing of External Cyli...
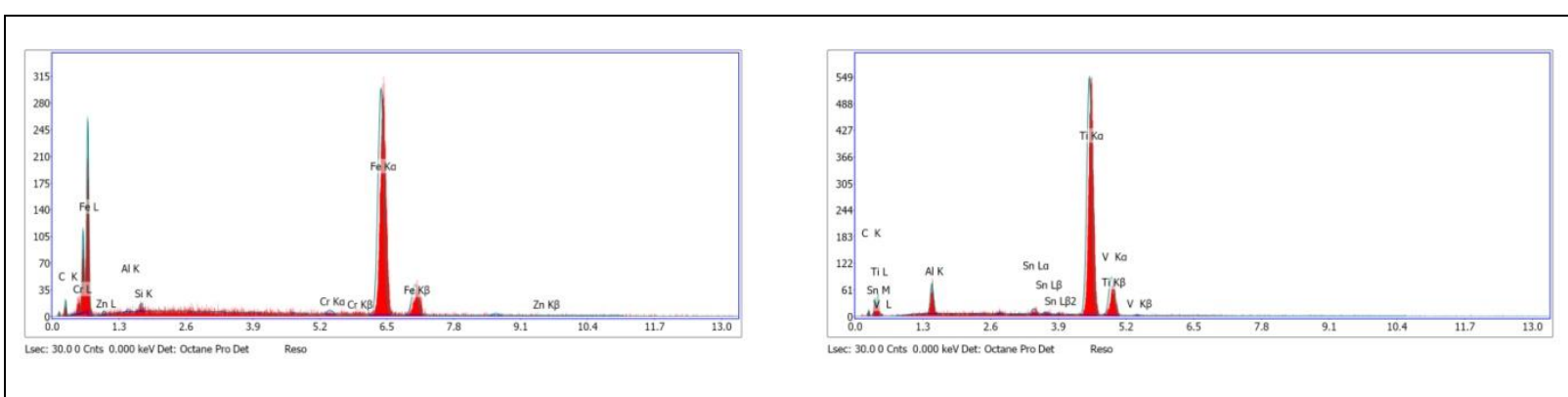

Fig. 5. (a) Ti 6Al 4V Composition by EDX and Fig.5.(b) EN8 Composition by EDX

\begin{tabular}{|c|c|}
\hline Parameter & Values \\
\hline Type of power supply & Continuous DC \\
\hline Current & $20 \mathrm{~A}$ \\
\hline Processing time & $08 \mathrm{~min}$ \\
\hline Voltage & $30 \mathrm{~V}$ \\
\hline Rotating speed & $60 \mathrm{rpm}$ \\
\hline Electrolyte pressure & $1 \mathrm{MPa}$ \\
\hline Electrolyte flow rate & $30 \mathrm{lit} / \mathrm{min}$ \\
\hline IEG & $0.75 \mathrm{~mm}$ \\
\hline
\end{tabular}

Tab. 1. Values of input and fixed parameters for experimentation of Ti alloy

\begin{tabular}{|c|c|}
\hline Parameter & Values \\
\hline Type of power supply & Continuous DC \\
\hline Current & $20 \mathrm{~A}$ \\
\hline Processing time & $12 \mathrm{~min}$ \\
\hline Voltage & $30 \mathrm{~V}$ \\
\hline Rotating speed & $60 \mathrm{rpm}$ \\
\hline Electrolyte pressure & $1 \mathrm{MPa}$ \\
\hline Electrolyte flow rate & $30 \mathrm{lit} / \mathrm{min}$ \\
\hline IEG & $0.75 \mathrm{~mm}$ \\
\hline
\end{tabular}

Tab. 2. Values of input and fixed parameters for experimentation of EN8 steel

\begin{tabular}{|c|c|c|c|}
\hline $\mathrm{Al}$ & $\mathrm{V}$ & $\mathrm{Ti}$ & $\mathrm{Sn}$ \\
\hline $5.0-6.0 \%$ & $3.0-4.0 \%$ & $85.0-90.0 \%$ & $0.50-0.90 \%$ \\
\hline
\end{tabular}

Tab. 3(a). Ti alloy Ti 6Al4V Composition data by EDX

\begin{tabular}{|c|c|c|c|c|}
\hline $\mathrm{C}$ & $\mathrm{Si}$ & $\mathrm{Mn}$ & $\mathrm{S}$ & $\mathrm{Fe}$ \\
\hline $0.35-0.45 \%$ & $0.05-0.35 \%$ & $0.6-1.0 \%$ & $0.06-0.10 \%$ & $80.50-90.00 \%$ \\
\hline
\end{tabular}

Tab. 3(b). EN8 steel Composition data by EDX

\section{Results \& discussion}

5.1. Experimental results of external cylindrical surfaces of titanium alloys

The surface roughness values obtained for Titanium alloys were noted After each experimentation. The values were noted for different processing time.Table 4 to 
8 presents the surface roughness (Ra) value, of work piece before and after machining for each experimental run. The calculated percentage improvement in surface roughness values (PIRa )are also shown. The initial and final $R_{a}$ values and the percentage improvement in surface roughness $\left(\operatorname{PIR}_{\mathrm{a}}\right)$ values both are presented in Table 4,5,6,7 and 8 for different processing time, electrolyte temperature, electrolyte composition and electrolyte concentration respectively. A higher value of PIR $_{a}$ represents lower value of final average surface roughness. Percentage improvement in average surface roughness value (PIR $\left.{ }_{a}\right)$ is used as process response. A higher value in PIR ${ }_{a}$ indicates better surface finish of work-surface as shown in Table 5. and this helps to study the material removal, finished surface characteristics, and surface integrity aspects of $\mathrm{ECH}$ process.

Fig.6.(a) and Fig.6.(b) Shows average surface roughness and average surface roughness 3D interactive image respectevely for $\mathrm{ECHed} \mathrm{Ti}$ alloy workpiece material captured by 3D profilometer. If average surface roughness values concerned, Fig.6.(c) and Fig. 6.(d) shows average surface roughness 3D Plot and average surface roughness bearing ratio respectively. Micro- structure study and Micro-structure characterization have been carried out to investigate the impact of the process on surface integrity aspects of the machined surface. SEM images of the cut surfaces have revealed that the fine surface finish was obtained when machining was done at a combination of lower levels of input process parameters. When machining was done at combination of higher levels of input process parameters, some burrs arise on the machined surface. Fig. 7. shows SEM photographs of electrochemically honed (ECHed) Ti alloy work piece surface (a) before ECH and (b) after ECH. As the ECH process is feasible for better material removal and shiny finishing look. It is evident from the plots that the surface roughness present in the surface after ECH is significantly reduced by this process.

\begin{tabular}{|l|l|c|c|c|c|c|c|}
\hline \multirow{2}{*}{$\begin{array}{c}\text { Trial } \\
\text { No }\end{array}$} & $\begin{array}{c}\text { Finishing } \\
\text { Time } \\
\end{array}$ & \multicolumn{2}{|c|}{$\begin{array}{c}\text { Top portion of } \\
\text { cylindrical })\end{array}$} & $\mathrm{R}_{\mathrm{a}}(\mu \mathrm{m})$ & \multicolumn{2}{c|}{$\begin{array}{c}\text { Middle portion of } \\
\text { cylindrical w/p }\end{array}$} & \multicolumn{2}{|c|}{$\begin{array}{c}\text { Bottom portion of } \\
\text { cylindrical w/p }\end{array}$} \\
\hline 1 & $\begin{array}{l}\text { Before } \\
\text { ECH }\end{array}$ & 1.46 & - & 1.43 & - & 1.50 & - \\
\hline 2 & 2 & 1.21 & 17.18 & 1.22 & 14.69 & 1.31 & 12.67 \\
\hline 3 & 4 & 1.01 & 30.82 & 1.04 & 27.27 & 1.12 & 25.33 \\
\hline 4 & 6 & 0.80 & 45.21 & 0.799 & 44.13 & 0.891 & 40.60 \\
\hline 5 & 8 & 0.38 & 79.45 & 0.201 & 85.94 & 0.314 & 79.07 \\
\hline 6 & 10 & 0.28 & 87.67 & 0.115 & 91.96 & 0.210 & 86.01 \\
\hline
\end{tabular}

Tab. 4. Average surface roughness and percentage of improvement in average surface roughness values at different finishing time 
Rao, P. S.; Jain, P. K. \& Dwivedi, D. K.: Electro Chemical Honing of External Cyli...

\begin{tabular}{|c|c|c|c|}
\hline $\begin{array}{c}\text { Finishing } \\
\text { Time } \\
\text { Period } \\
\text { (min) }\end{array}$ & $\begin{array}{c}\text { Top portion of } \\
\text { cylindrical w/p }\end{array}$ & $\begin{array}{c}\text { Middle portion of } \\
\text { cylindrical w/p }\end{array}$ & $\begin{array}{c}\text { Bottom portion of } \\
\text { cylindrical w/p }\end{array}$ \\
\hline $2-4$ & 13.64 & 12.58 & Increment of PIRa \\
\hline $4-6$ & 14.39 & 16.86 & 12.66 \\
\hline $6-8$ & 34.24 & 41.81 & 15.27 \\
\hline $8-10$ & 08.22 & 06.02 & 38.47 \\
\hline
\end{tabular}

Tab. 5. Increment in PIRa for different finishing time periods

\begin{tabular}{|c|c|c|c|c|c|c|c|c|c|}
\hline \multirow{2}{*}{$\begin{array}{c}\text { Electrolyte } \\
\text { Temperature }\end{array}$} & \multicolumn{3}{|c|}{$\begin{array}{c}\text { Top portion of } \\
\text { cylindrical w/p }\end{array}$} & \multicolumn{3}{c|}{$\begin{array}{c}\text { Middle portion of } \\
\text { cylindrical w/p }\end{array}$} & \multicolumn{3}{c|}{$\begin{array}{c}\text { Bottom portion of } \\
\text { cylindrical w/p }\end{array}$} \\
\cline { 2 - 10 } & Before & After & PIRa & Before & After & PIRa & Before & After & PIRa \\
\hline $20^{\circ} \mathrm{C}$ & 1.54 & 0.412 & 73.25 & 1.58 & 0.410 & 74.05 & 1.45 & 0.312 & 78.48 \\
\hline $25^{\circ} \mathrm{C}$ & 1.46 & 0.314 & 78.49 & 1.50 & 0.315 & 79.00 & 1.52 & 0.315 & 79.28 \\
\hline $30^{\circ} \mathrm{C}$ & 1.51 & 0.215 & 85.76 & 1.52 & 0.209 & 86.91 & 1.49 & 0.210 & 85.95 \\
\hline $35^{\circ} \mathrm{C}$ & 1.42 & 0.301 & 78.80 & 1.48 & 0.310 & 79.05 & 1.41 & 0.320 & 77.30 \\
\hline
\end{tabular}

Tab. 6. Average surface roughness (in $\mu \mathrm{m}$ ) and percentage of improvement in it for different electrolyte temperatures

\begin{tabular}{|c|c|c|c|c|c|c|c|c|c|}
\hline $\begin{array}{c}\text { Electrolyte } \\
\text { Concentration } \\
\text { (Single } \\
\text { Solution) }\end{array}$ & \multicolumn{3}{|c|}{$\begin{array}{c}\text { Top portion of } \\
\text { cylindrical w/p }\end{array}$} & \multicolumn{3}{c|}{$\begin{array}{c}\text { Middle portion of } \\
\text { cylindrical w/p }\end{array}$} & \multicolumn{3}{c|}{$\begin{array}{c}\text { Bottom portion of } \\
\text { cylindrical w/p }\end{array}$} \\
\cline { 2 - 11 } & Before & After & PIRa & Before & After & PIRa & Before & After & PIRa \\
\hline $5.0 \% \mathrm{NaCl}$ & 1.46 & 0.660 & 54.72 & 1.58 & 0.640 & 59.50 & 1.45 & 0.650 & 55.48 \\
\hline $7.5 \% \mathrm{NaCl}$ & 1.58 & 0.630 & 60.12 & 1.59 & 0.615 & 61.32 & 1.61 & 0.620 & 61.49 \\
\hline $10.0 \% \mathrm{NaCl}$ & 1.46 & 0.510 & 64.83 & 1.69 & 0.610 & 63.90 & 1.65 & 0.640 & 63.03 \\
\hline $12.5 \% \mathrm{NaCl}$ & 1.54 & 0.412 & 73.25 & 1.58 & 0.418 & 74.25 & 1.41 & 0.304 & 75.44 \\
\hline $15.0 \% \mathrm{NaCl}$ & 1.52 & 0.315 & 79.20 & 1.50 & 0.314 & 79.01 & 1.42 & 0.301 & 78.80 \\
\hline $17.5 \% \mathrm{NaCl}$ & 1.58 & 0.410 & 74.05 & 1.54 & 0.412 & 73.25 & 1.56 & 0.410 & 73.32 \\
\hline
\end{tabular}

Tab. 7 . Average surface roughness (in $\mu \mathrm{m}$ ) and percentage of improvement in it for different electrolyte compositions.For $100 \% \mathrm{NaCl}$ pure Electrolyte solution 


\begin{tabular}{|c|c|c|c|c|c|c|c|c|c|}
\hline $\begin{array}{c}\text { Electrolyte } \\
\text { Concentration } \\
\begin{array}{c}\text { Single } \\
\text { Solution) }\end{array}\end{array}$ & \multicolumn{3}{|c|}{$\begin{array}{c}\text { Top portion of } \\
\text { cylindrical w/p }\end{array}$} & \multicolumn{3}{c|}{$\begin{array}{c}\text { Middle portion of } \\
\text { cylindrical w/p }\end{array}$} & \multicolumn{3}{c|}{$\begin{array}{c}\text { Bottom portion of } \\
\text { cylindrical w/p }\end{array}$} \\
\cline { 2 - 11 } & Before & After & PIRt & Before & After & PIRt & Before & After & PIRt \\
\hline $5.0 \% \mathrm{NaNO}_{3}$ & 1.45 & 0.650 & 55.48 & 1.54 & 0.713 & 53.70 & 1.69 & 0.892 & 45.94 \\
\hline $7.5 \% \mathrm{NaNO}_{3}$ & 1.59 & 0.615 & 61.32 & 1.61 & 0.620 & 61.49 & 1.58 & 0.630 & 60.12 \\
\hline $10.0 \% \mathrm{NaNO}_{3}$ & 1.65 & 0.640 & 63.03 & 1.69 & 0.610 & 63.90 & 1.52 & 0.520 & 65.79 \\
\hline $12.5 \% \mathrm{NaNO}_{3}$ & 1.61 & 0.620 & 61.49 & 1.59 & 0.615 & 61.32 & 1.58 & 0.630 & 60.12 \\
\hline $15.0 \% \mathrm{NaNO}_{3}$ & 1.46 & 0.660 & 54.32 & 1.58 & 0.640 & 59.50 & 1.80 & 0.810 & 55.00 \\
\hline
\end{tabular}

Tab. 8 . Average surface roughness (in $\mu \mathrm{m}$ ) and percentage of improvement in it for different electrolyte compositions.For $100 \%$ NaNO3 pure electrolyte solution

From the experimental results, it can be observed that a very good improvement in average surface roughness $\mathrm{Ra}$ about $79.45 \%$ at top portion of the Cylindrical work piece, $85.94 \%$ at middle portion of the Cylindrical work piece and $79.07 \%$ at bottom portion of the Cylindrical work piece at a processing time of 08 minutes of Finishing Time as shown in Table 4 and Table 5. If total percentage improvement in surface roughness $\mathrm{Ra}$ is concerned, improvement about $34.24 \%$ at top portion of the Cylindrical work piece, $41.81 \%$ at middle portion of the Cylindrical work piece and $38.47 \%$ at bottom portion of the Cylindrical work piece respectively obtained at 08 minutes of Finishing Time as shown in Table 5.

If an electrolyte temperature is concerned, Table 6 results reveals that better surface finish at maximum $30^{\circ} \mathrm{C}$ of electrolyte temp and shows a very good percentage improvement in surface finish about $85.76 \%$ at top portion of the Cylindrical work piece, $86.91 \%$ at middle portion of the Cylindrical work piece and $85.95 \%$ at bottom portion of the Cylindrical work piece respectively.

From the results of $\mathrm{NaCl}$ electrolyte composition is concerned, the Table 7 describes that, the $100 \% \mathrm{NaCl}$ solution gives better surface finish and shows a very good percentage improvement in surface finish about $79.20 \%$ at top portion of the Cylindrical work piece, $79.01 \%$ at middle portion of the Cylindrical work piece and $78.80 \%$ at bottom portion of the Cylindrical work piece respectively at $15 \%$ of Concentration level of $\mathrm{NaCl}$ Solution. Fig.8.(a) shows AFM analysis of 2D histogram of ECHed surface and there is considerable decrease in surface roughness with increase in processing time. Fig.8.(b) shows AFM analysis 3D surface finish of ECHed surfaces and again there is considerable decrease in surface roughness with increase in processing time.

If $\mathrm{NaNO}_{3}$ electrolyte composition is concerned, from the Table 8 it is evident that, the $100 \% \mathrm{NaNO}_{3}$ solution gives better surface finish and shows a very good percentage improvement in surface finish about $63.03 \%$ at top portion of the Cylindrical work piece, $63.90 \%$ at middle portion of the Cylindrical work piece and $65.79 \%$ at bottom portion of the Cylindrical work piece respectively at $10 \%$ of Concentration level of $\mathrm{NaNO}_{3}$ Solution. 
Rao, P. S.; Jain, P. K. \& Dwivedi, D. K.: Electro Chemical Honing of External Cyli...

\subsection{Experimental results of external cylindrical surfaces of EN8 steel material}

Similarly, after experimentations the surface roughness values obtained for EN8 material were noted. The values were noted for different processing time. Table 9 to Table 13 presents the surface roughness ( $\mathrm{Ra}$ ) value, of work piece before and after machining for each experimental run. The calculated percentage improvement in surface roughness values (PIRa )are also shown. The initial and final $R_{a}$ values and the percentage improvement in surface roughness (PIR $\mathrm{P}_{\mathrm{a}}$ ) values both are presented in Table 9,10,11,12 and 13 for different processing time, electrolyte composition, electrolyte concentration and electrolyte temperature respectively. A higher value of PIR $_{a}$ represents lower value of final average surface roughness. Percentage improvement in average surface roughness value $\left(\mathrm{PIR}_{\mathrm{a}}\right)$ is used as process response and this helps to study the material removal, finished surface characteristics and surface integrity aspects of ECH process. A higher value in $\mathrm{PIR}_{\mathrm{a}}$ indicates better surface finish of work-surface as shown in Table 10.

If surface roughness values concerned, Fig.9.(a) and Fig. 9.(b) shows average surface roughness and average surface roughness $3 \mathrm{D}$ interactive image respectevely for ECHed workpiece material captured by profilometer. Fig.9.(c) and Fig. 9.(d) shows average surface roughness 3D Plot and average surface roughness bearing ratio respectively. Micro- structure study and Micro-structure characterization have been carried out to investigate the impact of the process on surface integrity aspects of the machined surface. SEM images of the cut surfaces have revealed that the fine surface finish was obtained when machining was done at a combination of lower levels of input process parameters. When machining was done at combination of higher levels of input process parameters, some burrs arise on the machined surface. Fig. 10. shows SEM photographs of electrochemically honed (ECHed) EN8 steel work piece surface (a) before ECH and (b) after ECH. It is clear from the plots that the surface roughness present in the surface after ECH is significantly reduced by the process. Hence the ECH process is feasible for better material removal and shiny finishing look.

\begin{tabular}{|l|l|c|c|c|c|c|c|}
\hline \multirow{2}{*}{$\begin{array}{c}\text { Trial } \\
\text { No }\end{array}$} & $\begin{array}{c}\text { Finishing } \\
\text { Time } \\
\end{array}$ & \multicolumn{2}{|c|}{$\begin{array}{c}\text { Top portion of } \\
\text { cylindrical w/p }\end{array}$} & $\mathrm{R}_{\mathrm{a}}(\mu \mathrm{m})$ & \multicolumn{2}{c|}{$\begin{array}{c}\text { Middle portion of } \\
\text { cylindrical w/p }\end{array}$} & \multicolumn{2}{c|}{$\begin{array}{c}\text { Bottom portion of } \\
\text { cylindrical w/p }\end{array}$} \\
\hline 1 & Before ECH & 4.55 & - & 4.69 & - & 4.63 & - \\
\hline 2 & 3 & 3.90 & 14.29 & 3.91 & 16.84 & 3.72 & 14.68 \\
\hline 3 & 6 & 3.50 & 23.08 & 3.30 & 29.64 & 3.15 & 27.75 \\
\hline 4 & 9 & 2.90 & 31.24 & 2.55 & 45.63 & 2.40 & 44.95 \\
\hline 5 & 12 & 0.904 & 80.13 & 0.954 & 79.75 & 0.940 & 78.44 \\
\hline 6 & 15 & 0.814 & 82.11 & 0.918 & 80.43 & 0.810 & 81.42 \\
\hline
\end{tabular}

Tab. 9. Average surface roughness and percentage of improvement in average surface roughness values at different finishing time 


\begin{tabular}{|c|c|c|c|}
\hline $\begin{array}{c}\text { Finishing } \\
\text { Time } \\
(\mathrm{min})\end{array}$ & $\begin{array}{c}\text { Top portion of } \\
\text { cylindrical w/p }\end{array}$ & $\begin{array}{c}\text { Middle portion of } \\
\text { cylindrical w/p }\end{array}$ & $\begin{array}{c}\text { Bottom portion of } \\
\text { cylindrical w/p }\end{array}$ \\
\cline { 2 - 4 } & Increment of PIR $\mathrm{a}$ & Increment of PIR $_{\mathrm{a}}$ & ${\text { Increment of } \mathrm{PIR}_{\mathrm{a}}}$ \\
\hline $3-6$ & 8.79 & 12.80 & 13.07 \\
\hline $6-9$ & 8.16 & 15.99 & 17.20 \\
\hline $9-12$ & 48.84 & 34.12 & 33.49 \\
\hline $12-15$ & 1.98 & 00.68 & 02.98 \\
\hline
\end{tabular}

Tab. 10. Increment in PIRa for different finishing time periods

\begin{tabular}{|c|c|c|c|c|c|c|c|c|c|}
\hline \multirow{2}{*}{$\begin{array}{l}\text { Electrolyte } \\
\text { Composition }\end{array}$} & \multicolumn{3}{|c|}{$\begin{array}{l}\text { Top portion of } \\
\text { cylindrical } \mathrm{w} / \mathrm{p}\end{array}$} & \multicolumn{3}{|c|}{$\begin{array}{l}\text { Middle portion of } \\
\text { cylindrical w/p }\end{array}$} & \multicolumn{3}{|c|}{$\begin{array}{l}\text { Bottom portion of } \\
\text { cylindrical } \mathrm{w} / \mathrm{p}\end{array}$} \\
\hline & Before & After & $\mathrm{PIR}_{\mathrm{a}}$ & Before & After & $\mathrm{PIR}_{\mathrm{a}}$ & Before & After & $\mathrm{PIR}_{\mathrm{a}}$ \\
\hline $\begin{array}{l}\text { 3/4 } \mathrm{NaCl}+ \\
1 / 4 \mathrm{NaNO}_{3} \\
\end{array}$ & 4.55 & 0.854 & 87.23 & 4.89 & 0.950 & 80.57 & 4.46 & 0.710 & 84.08 \\
\hline $\begin{array}{l}1 / 2 \mathrm{NaCl}+ \\
1 / 2 \mathrm{NaNO}_{3} \\
\end{array}$ & 4.06 & 0.901 & 77.83 & 4.29 & 0.910 & 78.79 & 4.10 & 0.801 & 80.46 \\
\hline $\begin{array}{l}1 / 4 \mathrm{NaCl}+ \\
3 / 4 \mathrm{NaNO}_{3}\end{array}$ & 4.16 & 0.980 & 76.44 & 4.21 & 1.050 & 75.06 & 4.19 & 0.910 & 79.00 \\
\hline
\end{tabular}

Tab. 11. Average surface roughness (in $\mu \mathrm{m}$ ) and percentage of improvement in it for different electrolyte compositions

\begin{tabular}{|c|c|c|c|c|c|c|c|c|c|}
\hline \multirow{2}{*}{$\begin{array}{c}\text { Electrolyte } \\
\text { Concentration }\end{array}$} & \multicolumn{3}{|c|}{$\begin{array}{c}\text { Top portion of } \\
\text { cylindrical w/p }\end{array}$} & \multicolumn{3}{c|}{$\begin{array}{c}\text { Middle portion of } \\
\text { cylindrical w/p }\end{array}$} & \multicolumn{3}{c|}{$\begin{array}{c}\text { Bottom portion of } \\
\text { cylindrical w/p }\end{array}$} \\
\cline { 2 - 11 } & Before & After & PIR $_{\text {a }}$ & Before & After & PIR $_{\mathrm{a}}$ & Before & After & PIR $_{\mathrm{a}}$ \\
\hline $5.0 \%$ & 4.18 & 0.979 & 76.58 & 4.20 & 1.049 & 75.08 & 4.19 & 0.915 & 78.40 \\
\hline $7.5 \%$ & 4.08 & 0.901 & 77.42 & 4.30 & 0.910 & 78.83 & 4.10 & 0.805 & 80.75 \\
\hline $10.0 \%$ & 4.54 & 0.855 & 81.17 & 4.90 & 0.949 & 80.63 & 4.45 & 0.710 & 84.04 \\
\hline $12.5 \%$ & 4.38 & 0.890 & 79.68 & 4.15 & 0.824 & 80.14 & 4.12 & 0.850 & 79.37 \\
\hline $15.0 \%$ & 4.17 & 0.990 & 76.26 & 4.10 & 0.940 & 77.07 & 4.18 & 0.900 & 78.47 \\
\hline
\end{tabular}

Tab. 12. Average surface roughness (in $\mu \mathrm{m}$ ) and percentage of improvement in it for different electrolyte concentrations

\begin{tabular}{|c|c|c|c|c|c|c|c|c|c|}
\hline \multirow{2}{*}{$\begin{array}{c}\text { Electrolyte } \\
\text { Temperature }\end{array}$} & \multicolumn{3}{|c|}{$\begin{array}{c}\text { Top portion of } \\
\text { cylindrical w/p }\end{array}$} & \multicolumn{3}{c|}{$\begin{array}{c}\text { Middle portion of } \\
\text { cylindrical w/p }\end{array}$} & \multicolumn{3}{c|}{$\begin{array}{c}\text { Bottom portion of } \\
\text { cylindrical w/p }\end{array}$} \\
\cline { 2 - 11 } & Before & After & PIR $_{\mathrm{a}}$ & Before & After & PIR $_{\mathrm{a}}$ & Before & After & PIR $_{\mathrm{a}}$ \\
\hline $25^{\circ} \mathrm{C}$ & 4.10 & 0.824 & 79.90 & 4.39 & 0.900 & 79.50 & 4.12 & 0.850 & 79.37 \\
\hline $30^{\circ} \mathrm{C}$ & 4.60 & 0.814 & 82.30 & 4.59 & 0.850 & 81.48 & 4.50 & 0.810 & 82.00 \\
\hline $35^{\circ} \mathrm{C}$ & 5.10 & 0.800 & 84.31 & 5.20 & 0.820 & 84.23 & 5.08 & 0.844 & 84.25 \\
\hline $40^{\circ} \mathrm{C}$ & 5.60 & 0.980 & 80.36 & 5.68 & 1.190 & 78.75 & 5.65 & 1.200 & 78.76 \\
\hline
\end{tabular}

Tab. 13. Average surface roughness (in $\mu \mathrm{m}$ ) and percentage of improvement in it for different electrolyte temperatures 
Rao, P. S.; Jain, P. K. \& Dwivedi, D. K.: Electro Chemical Honing of External Cyli...

It can be observed from the experimental results, that a very good improvement in average surface roughness $\mathrm{Ra}$ about $82.11 \%$ at top portion of the Cylindrical work piece, $80.43 \%$ at middle portion of the Cylindrical work piece and $81.42 \%$ at bottom portion of the Cylindrical work piece respectively at 12 minutes of Finishing Time as shown in Table 9 and Table 10. If total percentage improvement in surface roughness $\mathrm{Ra}$ concerned, improvement about $48.84 \%$ at top portion of the Cylindrical work piece, $34.12 \%$ at middle portion of the Cylindrical work piece and $33.49 \%$ at bottom portion of the Cylindrical work piece respectively obtained at 12 minutes of Finishing Time as shown in Table 10.

Even if an electrolyte is concerned, from the Table 11 it is evident that, the mixture of $3 / 4 \mathrm{NaCl}+1 / 4 \mathrm{NaNO}_{3}$ solution gives better surface finish and shows a very good percentage improvement in surface finish about $87.23 \%$ at top portion of the Cylindrical work piece, $80.57 \%$ at middle portion of the Cylindrical work piece and $84.08 \%$ at bottom portion of the Cylindrical work piece respectively. Fig.11.(a). shows AFM analysis of 2D histogram of ECHed surface and there is considerable decrease in surface roughness with increase in processing time.

Regarding concentration of an electrolyte ,it is again evident from the Table 12 that the maximum $10 \%$ of Concentration shows a very good percentage improvement in surface finish about $81.17 \%$ at top portion of the Cylindrical work piece, $80.63 \%$ at middle portion of the Cylindrical work piece and $84.04 \%$ at bottom portion of the Cylindrical work piece respectively. Fig.11.(b). shows AFM analysis 3D surface finish of ECHed surfaces and again there is considerable decrease in surface roughness with increase in processing time.

As per the electrolyte temperature concerned, Table 13 results reveals that better surface finish at maximum $35^{\circ} \mathrm{C}$ of electrolyte temp and shows a very good percentage improvement in surface finish about $84.31 \%$ at top portion of the Cylindrical work piece, $84.23 \%$ at middle portion of the Cylindrical work piece and $84.25 \%$ at bottom portion of the Cylindrical work piece respectively. Fig. 12. shows 2D Bearing ratio data of Ti alloy Ti6Al4V By AFM technique. and Fig. 13. shows 2D Bearing ratio data of EN8 by AFM technique.

\subsection{Effect of process parameters on ECH performance}

\subsubsection{Effect of finishing time}

It is found that the surface roughness values are decreasing with increasing processing time while the effect of processing time on $\mathrm{PIR}_{\mathrm{a}}$ is reverse. Table $4 \& 5$ and Table $9 \& 10$ presents the $R_{a}$ values and their percentage improvement (PIR $R_{a}$ ) for different processing time for Ti alloys and En8 respectively. It is evident from the results that the increment in percentage improvement values is most significant at initial stage and at later stage it is very less insignificant. Because initially the surface remains more irregular and therefore, the rate of electrochemical dissolution is high. But, at later stage of experimentation, the intensity of EC dissolution deceases as the surface gets smoothened. It is evident from Table 5, that up to processing time of 08 minutes, the rate of increment is significant while after processing time of 08 minutes the rate of increment is marginal and hence, 08 minutes was selected as optimal 
processing time for $\mathrm{Ti}$ alloys for further study as there is no furthet dissolution in the process.

Similarly , 12 minutes was selected as optimal processing time for EN8 Material for further study. It is evident from Table 10, that up to processing time of 12 minutes the rate of increment is significant.

\subsubsection{Effect of electrolyte composition}

From Table 7, it clearly indicates that a single solution of $100 \% \mathrm{NaCl}$ electrolyte with concentration of $15 \%$ gives better surface finish and shows a very good percentage improvement in surface finish of $\mathrm{Ti}$ alloy where as a single solution of $100 \%$ NaNO3 electrolyte with concentration of $10 \%$ gives better surface surface finish and shows a very good percentage improvement in surface finish as shown in Table 8 for Ti alloys.

It is evident from Table 11 , that a mixture of $3 / 4 \mathrm{NaCl}+1 / 4 \mathrm{NaNO}_{3}$ solution gives better surface finish and shows a very good percentage improvement in surface finish for EN8 Material. Increase of ions in an electrolyte of two different solutions increases the PIRa value. The conductivity of the electrolyte depends on electrolyte concentration as well as composition to get the reactions of anions and cations. As the electrolyte concentration is increased, more numbers of ions are available in the different composition solution of electrolytic dissolution which results in increasing electrolyte conductivity and increase in PIRa. But, the composition should be $3 / 4 \mathrm{NaCl}$ $+1 / 4 \mathrm{NaNO}_{3}$ to get better passivation effect. The electrolytic dissolution which results in increasing electrolyte conductivity increases the percentage improvement in surface roughness values and thus there is considerable decrease in surface roughness with increase in processing time. The conductivity of the electrolyte depends on electrolyte concentration as well as composition to get the reactions of anions and cations.Therefore the better passivation effect more amount of electrolytic dissolution on th process.

\subsubsection{Effect of electrolyte concentration}

In a mixture of $3 / 4 \mathrm{NaCl}+1 / 4 \mathrm{NaNO}_{3}$ solution an increase in electrolyte concentration continuously increases the $\mathrm{PIR}_{\mathrm{a}}$ value for EN8 material. The conductivity of the electrolyte depends on electrolyte concentration. It is evident from the Table 12, that as the electrolyte concentration is increased, more numbers of ions are available in the solution for electrolytic dissolution which results in increasing electrolyte conductivity and increase in PIR $\mathrm{a}_{\mathrm{a}}$. But, the concentration should be $\leq 10 \%$ to get better passivation effect. The electrolytic dissolution which results in increasing electrolyte conductivity increases the percentage improvement in surface roughness values.It is totally based on the process mixture of anions and cations.

But for Ti alloys, a single solution of $100 \% \mathrm{NaCl}$ electrolyte with concentration of $15 \%$ gives better surface finish and shows a very good percentage improvement in surface finish where as a single solution of $100 \% \mathrm{NaNO}_{3}$ electrolyte with concentration of $10 \%$ gives better surface finish and shows a very good percentage improvement in surface finish as shown in Table 7 and Table 8 respectively. 
Rao, P. S.; Jain, P. K. \& Dwivedi, D. K.: Electro Chemical Honing of External Cyli...

\subsubsection{Effect of electrolyte temperature}

It is obvious from the plots that surface finish improves with increasing electrolyte temperature. The variations of $P I R_{a}$ with electrolyte temperature are shown in Table 13. Electrolyte conductivity is very much sensitive towards electrolyte temperature and increases with it results in higher current density and thus provides the higher value of $P I R_{a}$. But, at higher temperature chance of formation of hydrogen gas at cathode is higher. It deteriorates the surface finish. At $35^{\circ} \mathrm{C}$, the highest $P I R_{a}$ values achieved. It is also evident from table that after $35^{\circ} \mathrm{C}$ the $\operatorname{PIR}_{\mathrm{a}}$ values start decreasing with increasing temperature. Increase in temperature increases electrolyte conductivity and consequently current density. Based on results, $35^{\circ} \mathrm{C}$ of electrolyte temperature is optimum for present study for EN8 material.

Similarly, $30^{\circ} \mathrm{C}$ of electrolyte temperature is optimum for further study for $\mathrm{Ti}$ alloy. Increase in temperature increases electrolyte conductivity and consequently current density as shown in Table 6. But in EN8 it is also evident from table that after $35^{\circ} \mathrm{C}$ the $\mathrm{PIR}_{\mathrm{a}}$ values start decreasing with increasing temperature. Increase in temperature increases electrolyte conductivity and consequently current density. It also effects the whole chemical process and gives the better response and results.

\subsection{Experimental results and data of Titanium alloy Ti6Al4V}

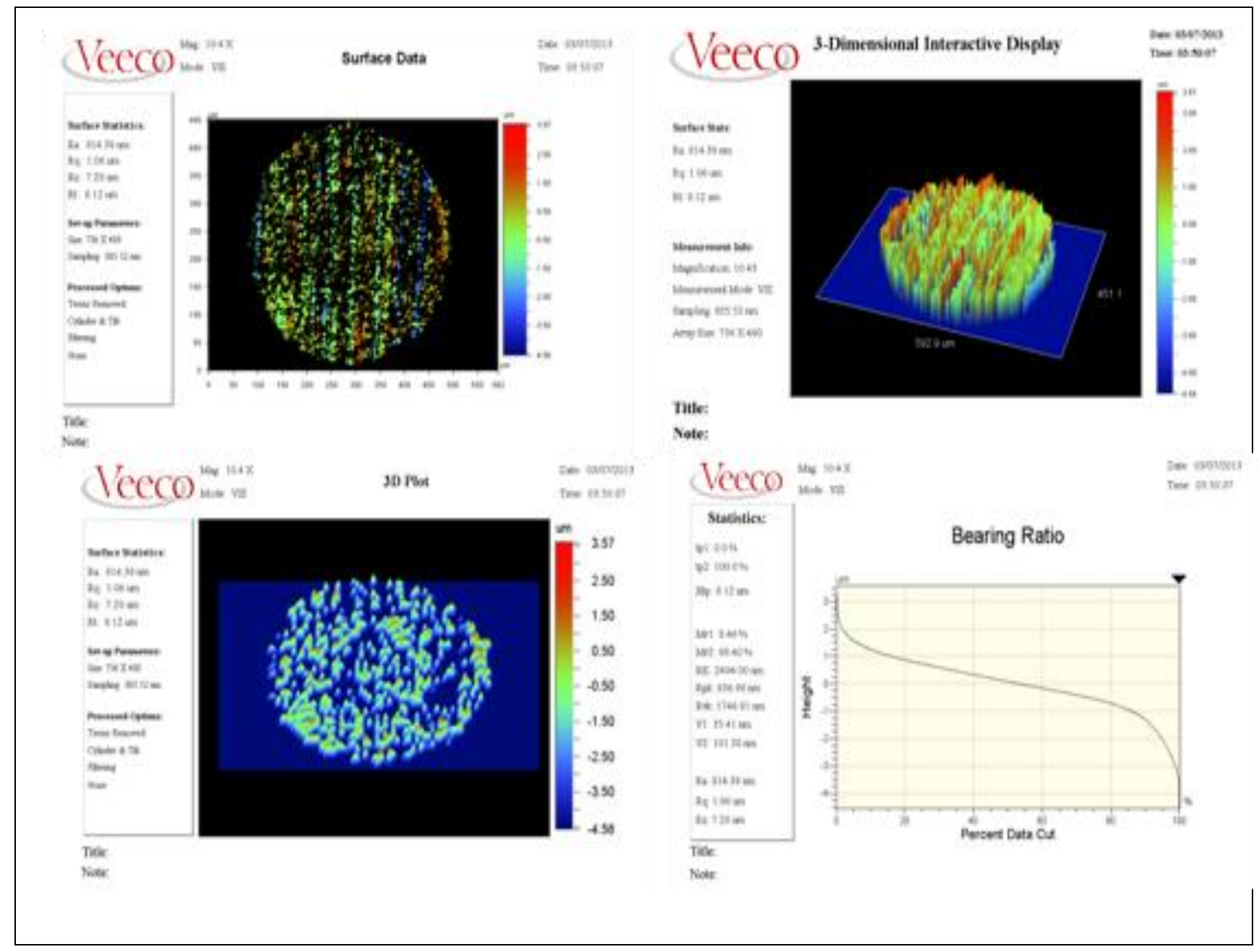

Fig.6. (a) Average surface roughness data, (b) Average surface roughness 3D data, (c) Average surface roughness 3D plot and (d) Bearing ratio data of Ti alloy Ti6Al4V 

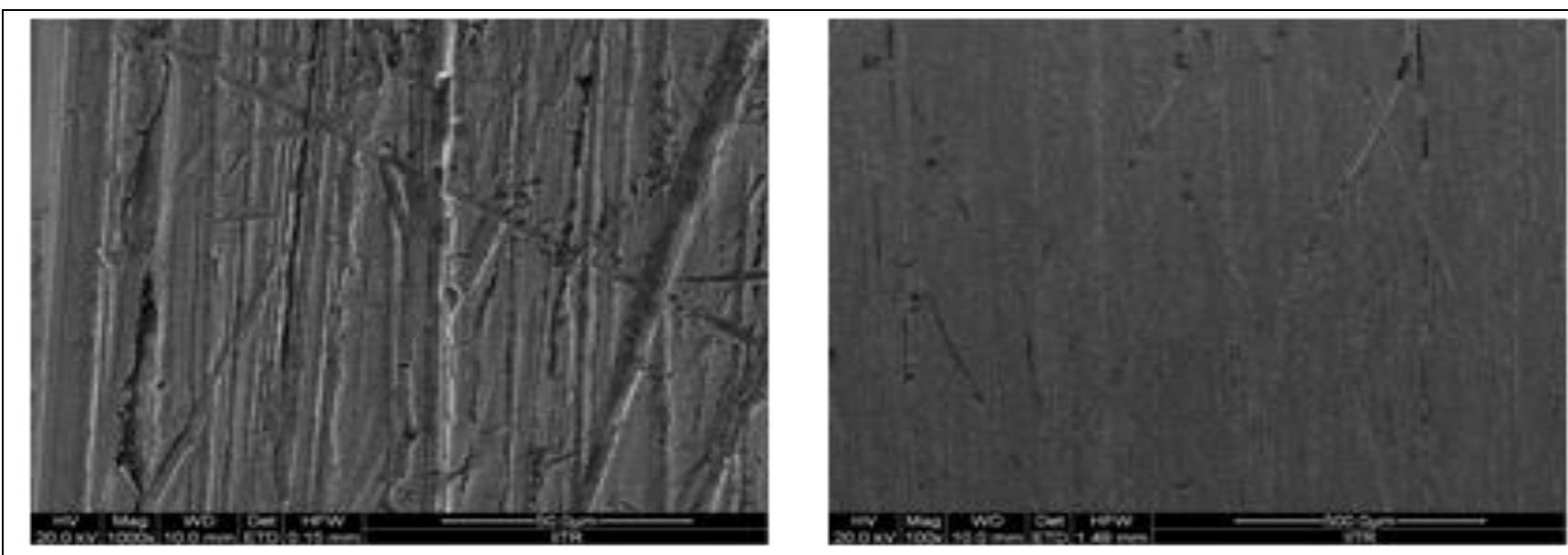

Fig. 7. SEM photographs of electrochemically honed (ECHed) Ti alloy Ti6Al4V surface (a) before ECH and (b) after ECH

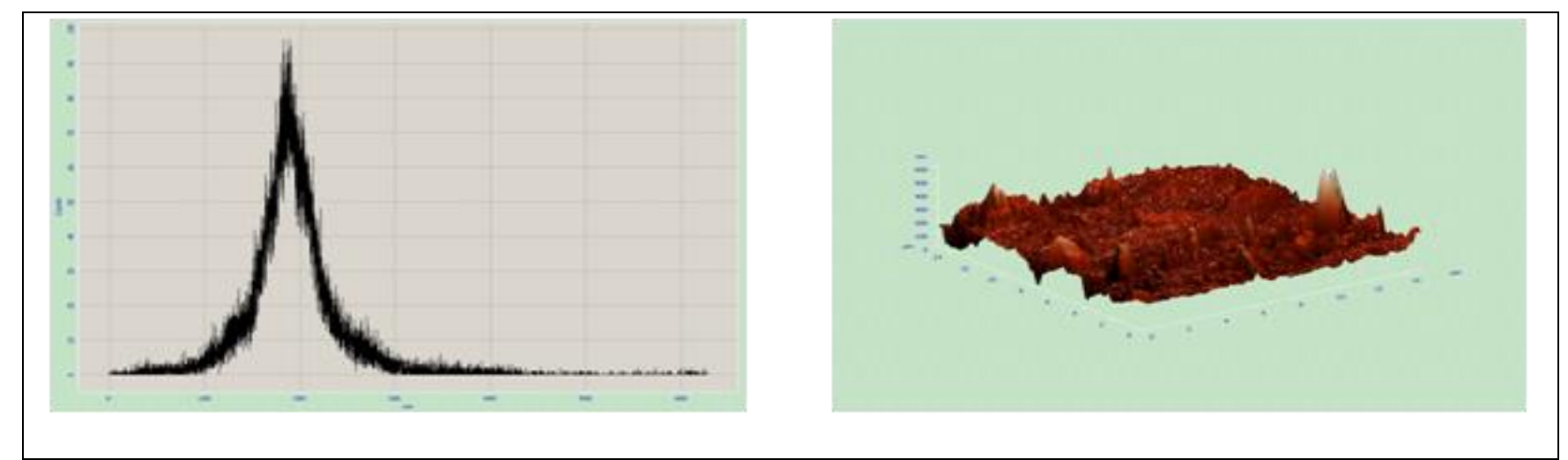

Fig. 8. (a) 2D histogram data of Ti alloy Ti6Al4V and (b) 3D surface finish of Ti alloy Ti6Al4V by AFM

\subsection{Experimental results and data of EN8 steel material}

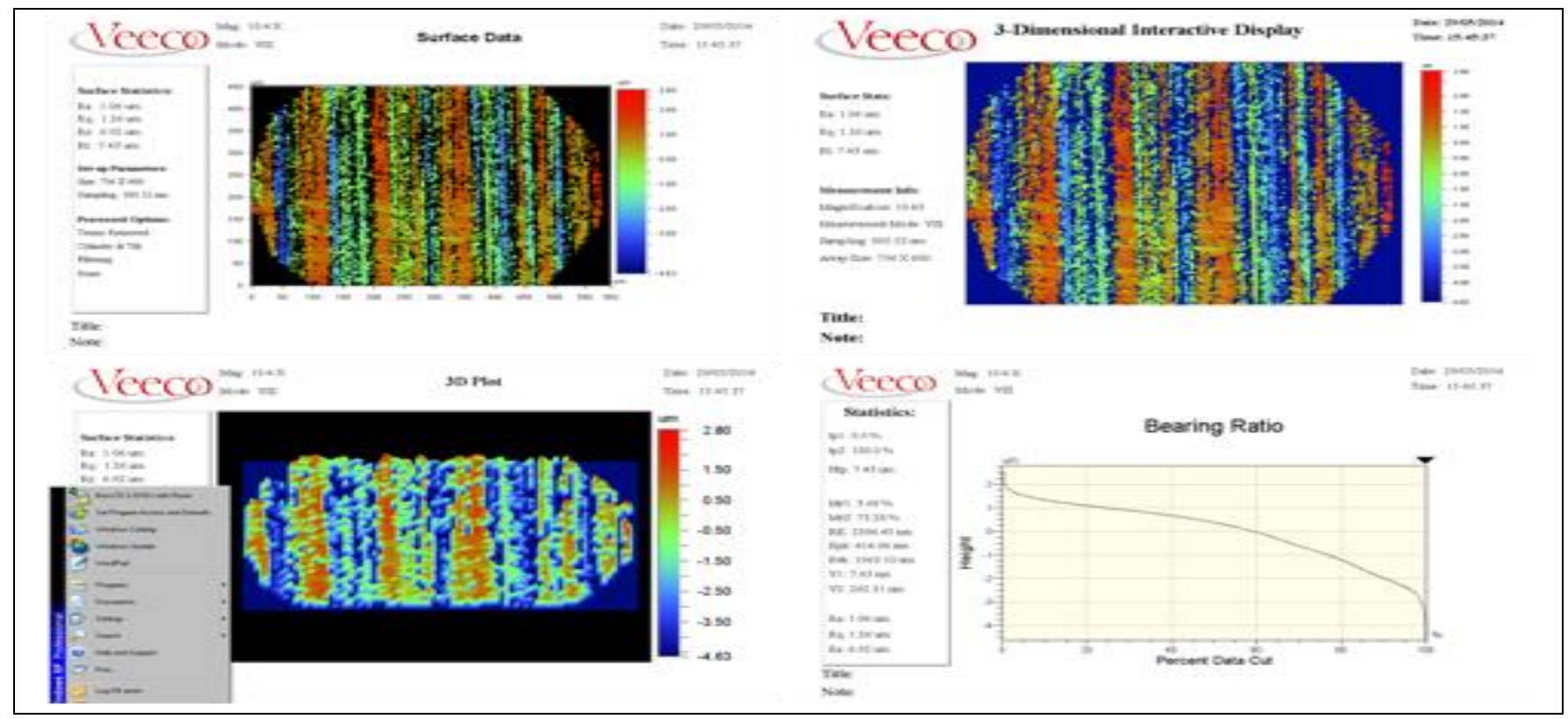

Fig. 9. (a) Average surface roughness data, (b) Average surface roughness 3D data, (c) Average surface roughness 3D plot and (d) Bearing ratio data of EN8 material 
Rao, P. S.; Jain, P. K. \& Dwivedi, D. K.: Electro Chemical Honing of External Cyli...

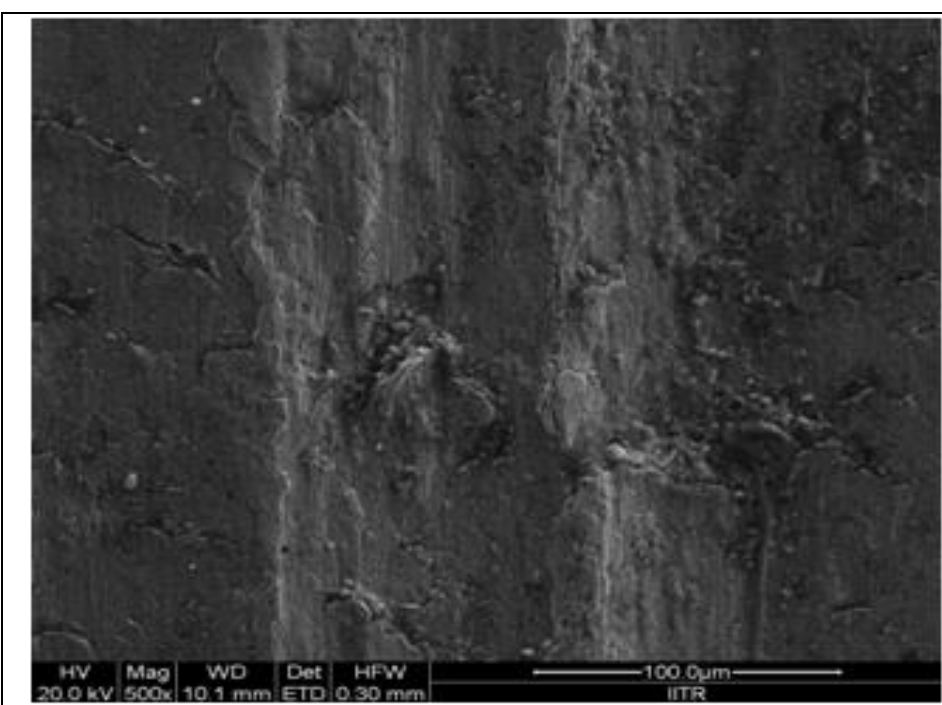

(a)

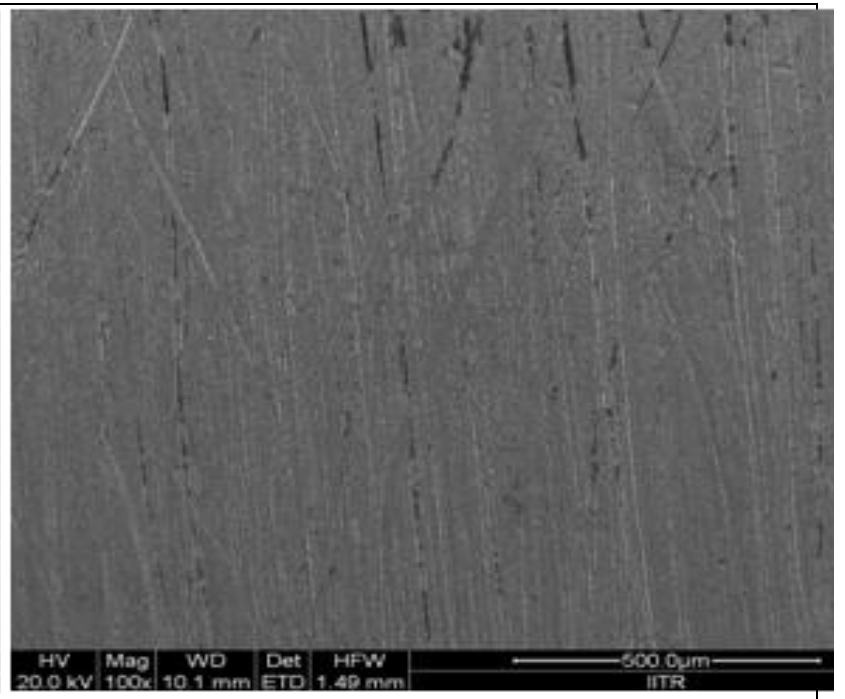

(b)

Fig. 10. SEM photographs of electrochemically honed (ECHed) EN8 material surface (a) before ECH and (b) after ECH

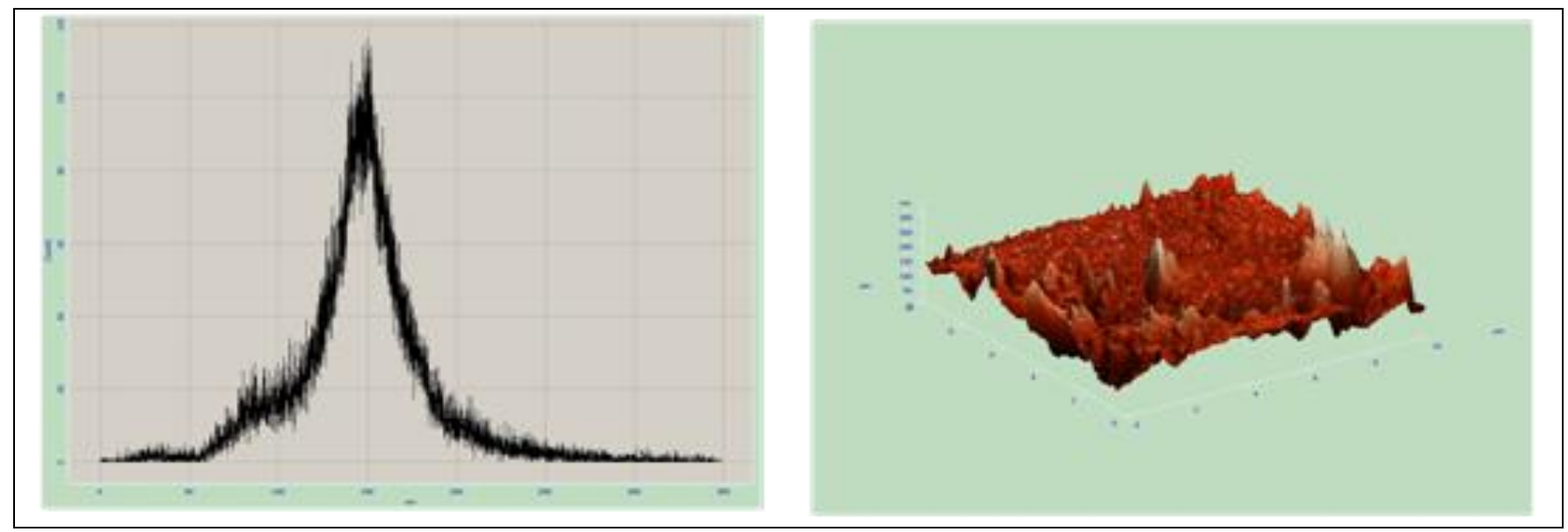

Fig. 11.(a) 2D histogram data of EN8 material by AFM and (b) 3D surface finish of EN8 material by AFM

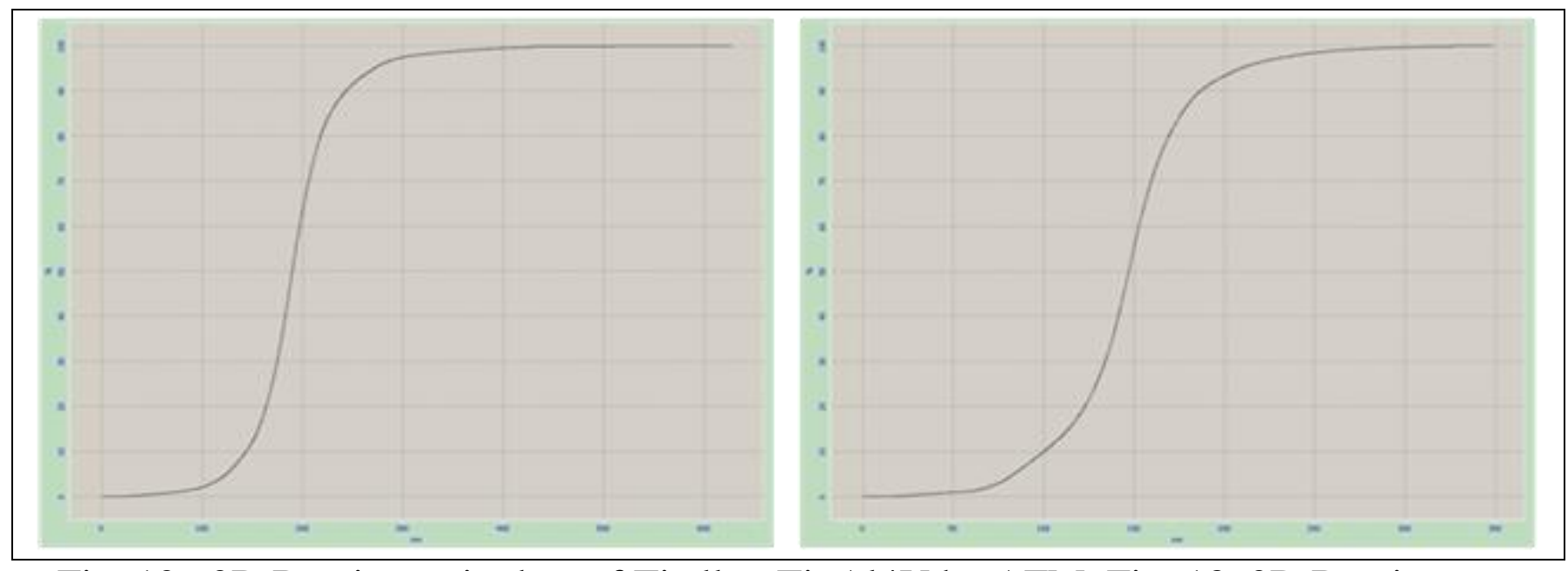

Fig. 12. 2D Bearing ratio data of Ti alloy Ti6Al4V by AFM Fig. 13. 2D Bearing ratio data of EN8 steel by AFM 


\section{Conclusion and future scope}

An experimental conclusion can be made based upon the results of experiments obtained by ECH process, 12 minutes as finishing time, a mixtute of $3 / 4 \mathrm{NaCl}+1 / 4$ $\mathrm{NaNO}_{3}$ as electrolyte composition, a level of $10 \%$ of electrolyte concentration and a temp of $35^{\circ} \mathrm{C}$ as electrolyte temperature were found optimum for precision super finishing of external cylindrical surfaces of EN8 Steel material. The results shows that, all the four parameters are highly important to achieve the better surface finish and also for better amount of material removal.

Similarly, 08 minutes as finishing time, a single solution of $100 \% \mathrm{NaCl}$ electrolyte composition of $15 \%$ concentration, a single solution of $100 \% \mathrm{NaNO}_{3}$ electrolyte composition of $10 \%$ concentration and a temp of $30^{\circ} \mathrm{C}$ as electrolyte temperature were found optimum for precision super finishing of external cylindrical surfaces of $\mathrm{Ti}$ alloy material. The results shows that, all the four parameters are highly important to achieve the better surface finish and also for better amount of material removal.

The hybrid process established the feasibility of using ECH process for high precision finishing of $\mathrm{Ti}$ alloy and EN8 steel material to improve the microtopographical characteristics.In this work, an attempt was made to study the effects of input process parameters like processing time, electrolyte composition, electrolyte concentration and electrolyte temperature and also found that they play a significant role in the minimization of roughness. The study illustrates that initially the processing rate is high, but it slows down as the processing time increases. But even with increased processing time, its productivity and mechanical properties are good enough. It is also found, that the process is highly capable of reducing the irregularities on cylinder surfaces. It is even evident that, the processing time has immense influence on material removal mechanism of the process.

However, like most of the hybrid machining processes, ECH is also in the development phase and therefore, a sustained global research is still required to perform it into other tougher and hardest materials as well as other process parameters. Further research could consider the study of effect of different parameters like Inter electrode gap, voltage, current, honing abrasive grit size and other different electrolyte related parameters etc.Further study is in progress to look into other response parameters like cylindricity,circularity,diameter decrease rate and axis deviation of the cylindrical components for Titanium and EN8 steel material.

\section{References}

Bannard, J. (1976). On the electrochemical machining of some titanium alloys in bromide electrolytes, J. of Applied Electrochemistry, Vol. 6, pp. 477-483

Benedict, G.F. (1987). Nontraditional Manufacturing Processes, (Marcel Dekker, New York)

Budzynski, A.(1989). Theoretical and experimental research on process of electrochemical honing (ECH).,ISEM-9, Nagoya

Burr, A.E. De and Oliver D.A. (1968). Electrochemical Machining, Macdonald \& Co. Ltd 
Rao, P. S.; Jain, P. K. \& Dwivedi, D. K.: Electro Chemical Honing of External Cyli...

Chen, C.P. , Liu, j. , Wei, G. C. ,Wan, C. B. and Wan, J. (1981). Electro-chemical honing of gears - A new method of gear finishing, Annals of CIRP, 30, 103-106 Dubey, A.K. (2008). Experimental investigations on electrochemical honing. Proc. IMechE, Part B: J. Engineering Manufacture, Vol. 222, No. B3, pp. 413-426

Dubey, A.K. (2006). Development of the setup and performance optimization of electrochemical honing process, $P h D$ Thesis, IIT Roorkee

El-Hofi, H. (2005). Fundamentals of Machining Processes, McGraw-Hill Book Co., New York

He, F. , Zhang, W. and Nezu, K. (2000). A precision machining of gears (slowscanning field controlled electrochemical honing), JSME International Journal Series $C, 43$, No. 2, 486-491

$\mathrm{Lu}, \mathrm{X}$. and Leng, Y. (2005). Electrochemical micromachining of titanium surfaces for biomedical applications, J. of Materials Processing Technology, Vol. 169, pp. 173178

Misra, J.P. , Jain, P.K. and Dwivedi, D.K. (2011). Electrochemical honing-A novel technique for gear finishing, DAAAM International Scientific Book ,Chapter 29, 365382

Misra, J.P., Jain, P.K. and Sevak, R. (2012). ECH of spur gears-A step towards commercialization, DAAAM International Scientific Book, Chapter 17, 197-212

Misra, J.P. , Jain, P.K. , Dwivedi, D.K. and Mehta, N.K. (2013). Study of time dependent behavior of electro chemical honing $(\mathrm{ECH})$ of bevel gears, 24th DAAAM International symposium on intelligent manufacturing and automation 2013, J. of Procedia Engineering, 64, 1259-1266

Merchant, M.E. (1961) The manufacturing system concept in production engineering research, CIRP Annals, 10, 77-83

Pandey, P.C. and Shan, H.S. (1980). Modern Machining Processes, (Tata McGrawHill Publishing Company, New Delhi)

Rao, P.S. , Jain, P.K. and Dwivedi, D.K.(2014). Electro chemical honing (ECH) of external cylindrical surfaces of titanium alloys, 25th DAAAM International symposium on intelligent manufacturing and automation, J. of Procedia Engineering, 100, 936-945

Rao, P.S. , Jain, P.K. and Dwivedi, D.K. (2015). Precision finishing of external cylindrical surfaces of EN8 steel by electro chemical honing $(\mathrm{ECH})$ process using OFAT technique, 4th International Conference on Materials Processing and Characterization, J. of Materials Today Proceedings, 2,3220-3229

Shaikh, J.H. and Jain, N.K. (2013). High quality finishing of bevel gears by ECH, DAAAM International Scientific Book, Chapter 41, 697-710

Singh, H. and Jain, P.K. (2013). Remanufacturing with ECH, 24th DAAAM International symposium on intelligent manufacturing and automation, $J$. of Procedia Engineering, 69,1100-1104

Sunil, J. Raykar. , D'Addona, D.M. and Kramar, Davorin. (2014). Analysis of surface topology in dry machining of EN-8 steel, Procedia Material Science, 6, 5559 